\title{
Increased IFN- $\gamma$-producing Th17/Th1 cells and their association with lung function and current smoking status in patients with chronic obstructive pulmonary disease
}

Weihan $\mathrm{Xu}^{1,2}$, Ruimin $\mathrm{Li}^{2,3}$ and Yongchang Sun ${ }^{2,4^{*}}$

\begin{abstract}
Background: Th17 cells are believed to be important proinflammatory cells in the pathogenesis of chronic obstructive pulmonary disease (COPD). Recent evidence demonstrates that Th17 cells display substantial developmental plasticity, giving rise to Th17/Th1 cells that secret both IL-17 and IFN- $\gamma$ and are more pathogenic in inflammatory diseases. The aim of this study was to examine the distribution of circulating Th17/Th1 subpopulation and its association with disease severity in patients with COPD.
\end{abstract}

Methods: Blood samples were obtained from 21 never-smokers, 31 smokers with normal lung function and 83 patients with COPD. The frequencies of Th17 cells and the Th17/Th1 subset were measured using flow cytometry. Plasma concentrations of IL-6, transforming growth factor (TGF)- $\beta 1$ and IL-12 were determined by ELISA. The associations of Th17/Th1 cells with lung function and smoking were evaluated.

Results: In peripheral blood, significantly increased proportions of Th17/Th1 cells among CD4 cells and Th17 cells were found in COPD patients compared with never-smokers and smokers with normal lung function. The percentages of Th17/Th1 cells showed correlations with forced expiratory volume in $1\left(\mathrm{FEV}_{1}\right) \%$ predicted value $(r=-0.244, p<0.05)$, and higher proportions of Th17/Th1 cells in GOLD stage IV patients compared with stage I patients. The percentages of Th17/Th1 cells were significantly higher in current smokers compared with ex-smoker COPD patients, and positively correlated with pack-years of smoking $(r=0.352, p<0.01)$. The plasma concentrations of IL-6, TGF- $\beta 1$ and IL-12 were significantly increased in patients with COPD compared with never-smokers and smokers with normal lung function.

Conclusion: Our results revealed correlations of proportions of IFN- $\gamma$-producing Th17/Th1 cells with lung function and smoking, suggesting that increased Th17/Th1 cells may play a role in COPD progression.

Keywords: Lymphocyte, CD4 ${ }^{+}$T cell, Inflammation, COPD, Cytokines, Th17 plasticity

\section{Background}

Chronic obstructive pulmonary disease (COPD) is characterized by persistent airflow limitation and an enhanced chronic inflammatory response to noxious particles or gases, particularly cigarette smoke [1, 2]. Evidence shows that chronic inflammation, present in the peripheral and central airways, lung parenchyma and

\footnotetext{
* Correspondence: suny@bjmu.edu.cn

${ }^{2}$ Department of Respiratory Medicine, Beijing Tongren Hospital, Capital Medical University, Beijing, China

${ }^{4}$ Department of Respiratory and Critical Care Medicine, Peking University Third Hospital, Beijing, China

Full list of author information is available at the end of the article
}

the systemic circulation, contributes significantly to the development and progression of COPD [3-5].

Inflammation in COPD was believed to be driven by $\mathrm{T}$ helper 1 (Th1) response, but accumulating evidence supports a critical role of Th17 response in the disease. Increased Th17 cells were found in the bronchial submucosa, airway epithelium, lung tissue, bronchoalveolar lavage and peripheral blood from COPD patients compared with smokers without COPD and healthy subjects [4, 6-8]. Inverse correlations were observed between Th17 cells and forced expiratory volume in $1 \mathrm{~s}\left(\mathrm{FEV}_{1}\right)$ percentage predicted in COPD [8]. IL-17 orchestrates the 
recruitment of neutrophils and macrophages by enhancing production of a variety of chemokines, such as IL-1 $\beta$, IL-6, TNF- $\alpha$, CXCL8, granulocyte colony-stimulating factor (G-CSF), and GM-CSF from inflammatory and structural cells of the lung $[9,10]$. Moreover, a recent study found that IL-17A contributed to cigarette smoke-induced lymphoid neogenesis of late-stage COPD, suggesting that IL-17A is critical in chronic inflammation and adaptive immune responses in COPD [11]. However, IL-17A expression is not sufficient to define the pathogenic activity of Th17 cells, which represent heterogeneous populations with distinct trafficking profiles and abilities to provoke autoimmune diseases [12].

Recent studies identified a subset of IL-17/IFN- $\gamma$ doublepositive $\mathrm{T}$ cells, namely Th17/Th1cells, in inflamed tissues or blood from both humans and mice with chronic inflammatory disorders [13]. Th17 cells have been found to exhibit high plasticity because they convert to Th17/Th1 cells under inflammatory environments, especially IL-12-rich microenvironment, whereas Th1 cells cannot convert to Th17 cells $[14,15]$. Th17/Th1 cells coexpress both Th1 and Th17 transcription factors consisting of T-box expressed in $\mathrm{T}$ cells (T-bet) and RAR-related orphan receptor (ROR)yt, and differ from Th1 cells on CD161, IL-17 receptor E and CCR6 expressions $[13,15]$. Th17/Th1 cells display pro-inflammatory characteristics by higher expression of genes encoding cytokines, chemokines and transcription factors, such as $C x c l 3, C c l 3, C c l 4, C c l 5, I l 22, I l 3, I c o s, T b x 21$ and Stat4, and downregulated expression of genes encoding cytokines associated with immunoregulation, such as I19, Il10, Ahr and Maf (which encode molecules involved in the regulation if IL-10 production), and therefore can be more pathogenic and aggressive [16]. Recent studies revealed the clinical relevance of Th17/Th1 cells in patients with autoimmune diseases and diabetes [17-19]. Moreover, Th17/ Th1 cells are resistant to glucocorticoid-mediated $\mathrm{T}$ cell suppression, which may be of clinical implication in inflammation unresponsive to glucocorticoids, such as COPD.

Therefore, we examined the distribution of this novel pro-inflammatory Th17/Th1 cells in the peripheral blood of patients with COPD and smokers by using flow cytometry and correlated the frequency of Th17/Th1 subset with Global Initiative for Chronic Obstructive Lung Disease (GOLD) classification, lung function parameters and smoking status.

\section{Methods \\ Subjects}

The study population was recruited in Beijing Tongren Hospital and Beijing Daxing Teaching Hospital, Capital Medical University, China. There were 83 stable COPD patients, all current or former smokers, and 31 smokers and 21 never-smokers with normal lung function. Peripheral blood was obtained from all participants after written informed consent. The study was approved by the local research ethical committee (TRECKT 2008-14).

The diagnosis of COPD was established according to the criteria by GOLD guidelines [2]. COPD patients had an impaired pulmonary function (post-bronchodilator $\mathrm{FEV}_{1} /$ forced vital capacity $<70 \%$ ) and a smoking history of $\geq 20$ pack-years. All participants with COPD were stable and had no exacerbations for $\geq 3$ months prior to recruitment. Individuals with upper respiratory tract infection in the past 4 weeks, restrictive lung diseases, other chronic systemic inflammatory diseases, such as rheumatoid arthritis (RA), inflammatory bowel disease, were excluded. Some patients were treated with inhaled bronchodilators and inhaled corticosteroids (ICS), but did not receive oral steroid therapy. Individuals with a smoking history of $\geq 20$ pack-years and post-bronchodilator $\mathrm{FEV}_{1} / \mathrm{FVC}>70 \%$ and $\mathrm{FEV}_{1}>$ $80 \%$ predicted value were categorized as smokers with normal lung function, including current and ex-smokers. Ex-smokers were defined as those quitting smoking for a minimum of 2 years before entering the study.

\section{Cell collection and flow cytometry analysis}

Peripheral blood samples were drawn in ethylenediaminetetraacetic acid tubes from all participants and separated to peripheral blood mononuclear cells (PBMC) by centrifugation on Ficoll-Paque Plus solution (Amersham Biosciences,

Table 1 The demographic and clinical characteristics of all participants

\begin{tabular}{|c|c|c|c|}
\hline No. of Subjects & $\begin{array}{l}\text { Never-smokers } \\
n=21\end{array}$ & $\begin{array}{l}\text { Smokers } \\
n=31\end{array}$ & $\begin{array}{l}\text { Patients with COPD } \\
n=83\end{array}$ \\
\hline Age (years) & $64.9 \pm 6.5$ & $63.7 \pm 8.9$ & $67.0 \pm 8.4$ \\
\hline Male/Female & $19 / 0$ & $29 / 2$ & $79 / 4$ \\
\hline Current/ex-smokers & $0 / 0$ & $27 / 4$ & $36 / 47$ \\
\hline smoking, pack-yrs & 0 & $40(23-78)$ & $48(31-109)$ \\
\hline $\mathrm{FEV}_{1} \%$ predicted & $93.5 \pm 8.2$ & $90.5 \pm 6.4$ & $49.3 \pm 10.7$ \\
\hline $\mathrm{FEV}_{1} / \mathrm{FVC} \%$ & $78.4 \pm 5.1$ & $72.9 \pm 6.0$ & $51.6 \pm 9.3$ \\
\hline Inhaled corticosteroid use & 0 & 0 & 46 \\
\hline
\end{tabular}

Values are presented median (IQR) for smoking history, mean and standard deviation for age, $\mathrm{FEV}_{1} \%$ predicted and $\mathrm{FEV} / \mathrm{FVC} \%$, $\mathrm{n}$ for all others. COPD chronic obstructive pulmonary disease, $F E V_{1}$ forced expiratory volume in $1 \mathrm{~s}, F V C$ forced vital capacity 


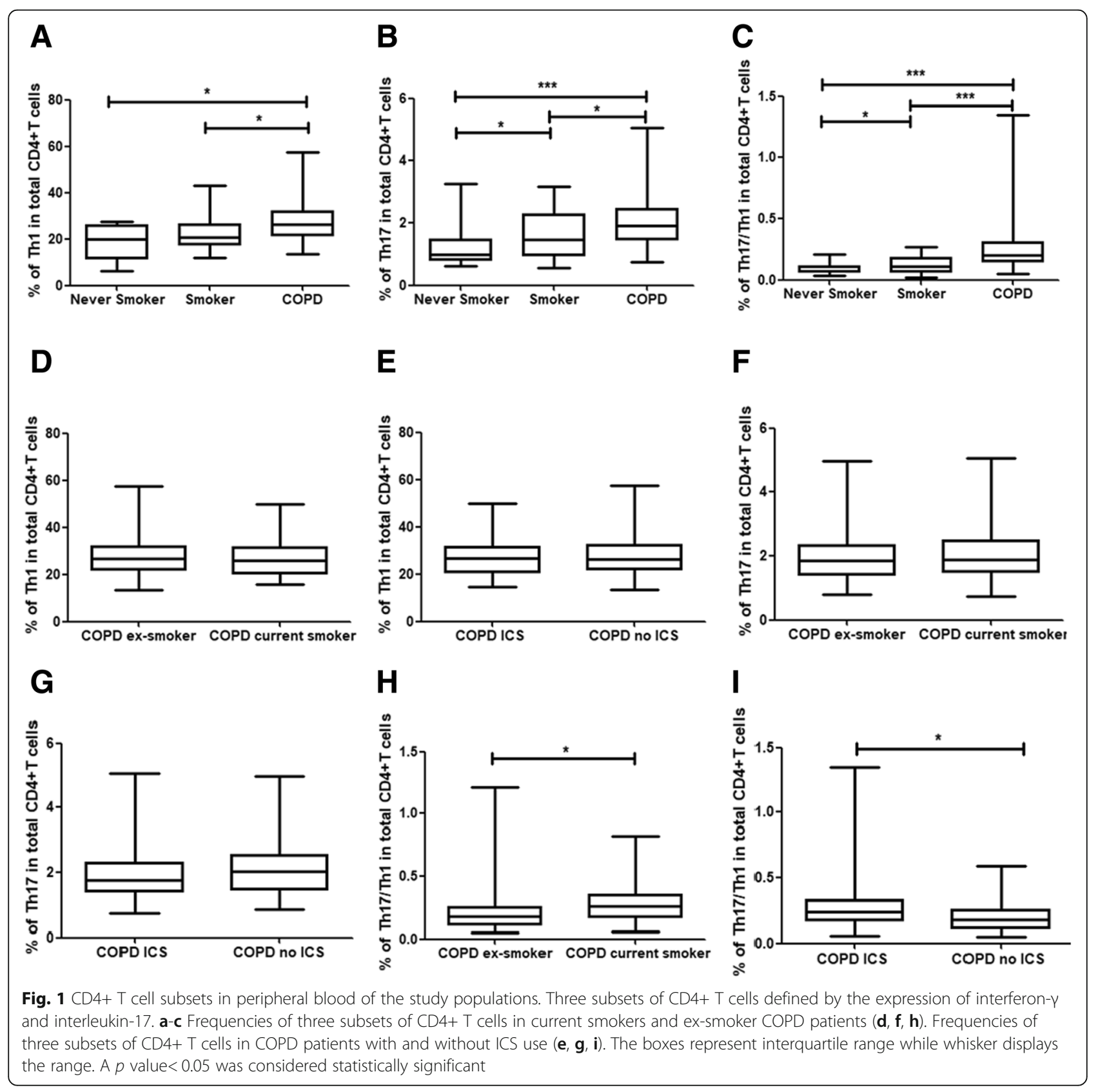

Amersham, Bucks, UK), at $400 \times \mathrm{g}$ for $20 \mathrm{~min}$ at $21^{\circ} \mathrm{C}$. Then, PBMCs were washed by divalent cation-free Hanks balanced salt solution at $300 \times \mathrm{g}$ for $5 \mathrm{~min}$ at $4{ }^{\circ} \mathrm{C}$ and resuspended at $10^{6}$ cells $/ \mathrm{ml}$ in RPMI-1640 medium.

For cytokine analysis, freshly processed human PBMCs were stimulated with $50 \mathrm{ng} / \mathrm{ml}$ of phorbol 12-myristate 13 acetate and $500 \mathrm{ng} / \mathrm{ml}$ of ionomycin and incubated at $37^{\circ} \mathrm{C}$ in the presence of $5 \mu \mathrm{g} / \mathrm{ml}$ Brefeldin A. After $5 \mathrm{~h}$ cells were collected and stained as previously demonstrated with antihCD4-PE (BD Biosciences, San jose, California, USA) for $30 \mathrm{~min}$ at room temperature. For detection of intracellular cytokines, cells were subsequently stained with anti-hIL-17-
FITC (eBioscience, San Diego, California), anti-hIFN- $\gamma$ FITC (eBioscience) after fixation and permeabilization. Cells were analyzed by FACS-Calibur (BD Biosciences) and isotype control was used to set gates. A total of $1 \times 10^{6}$ events were examined for each subject. The data were presented using proportions of cells and were analyzed by FlowJo software (Tree Star, Ashland, OR, USA).

\section{Cytokine enzyme-linked immunosorbent assay}

The concentrations of IL-6, TGF- $\beta 1$ and IL- 12 in the plasma from the participants were measured by enzymelinked immunosorbent assay (ELISA, eBioscience, San 

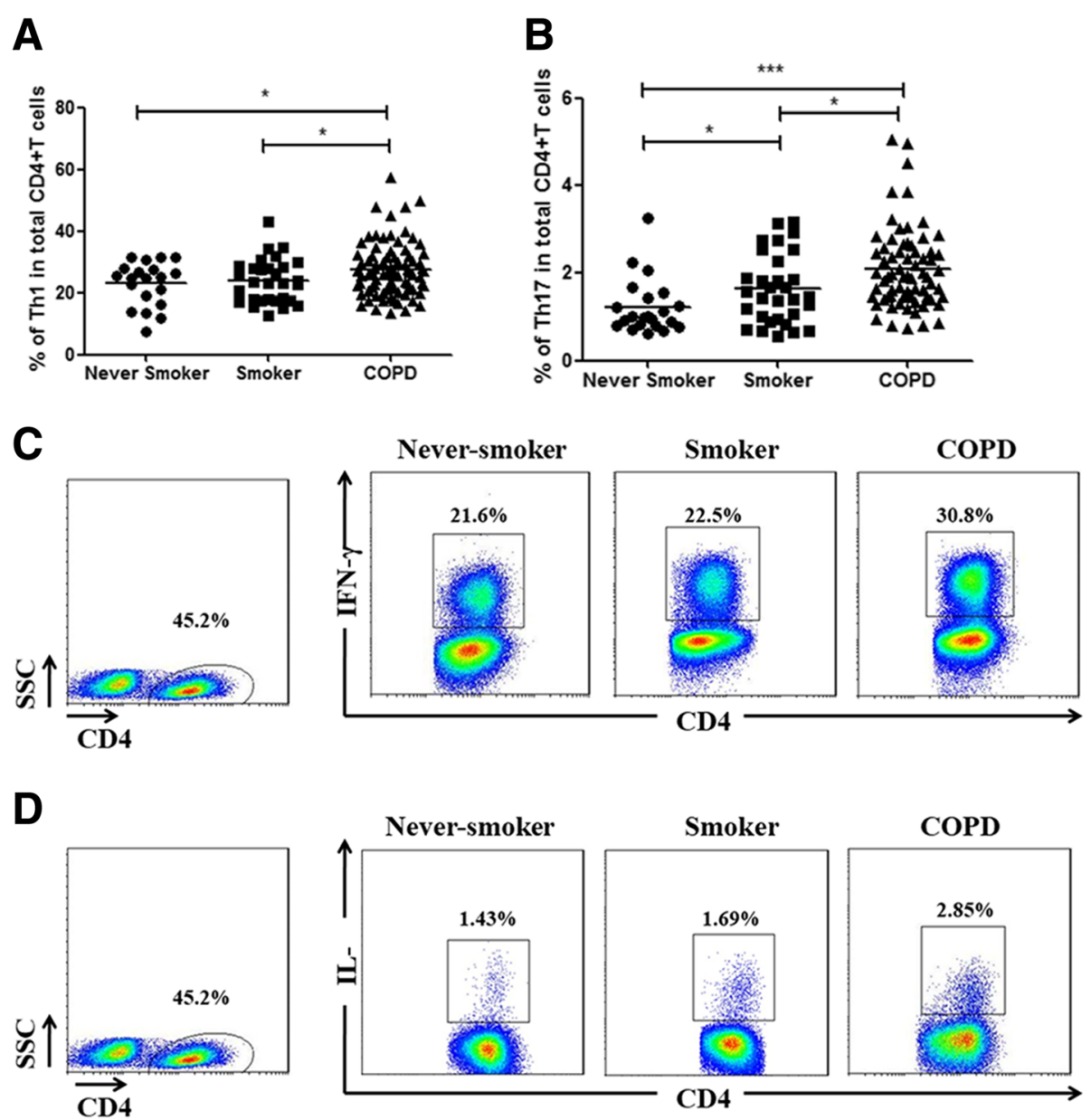

Fig. $2 \mathrm{CD}^{+} \mathrm{T}$ cell subsets in peripheral blood under physiological and disease conditions. Three subsets of $C D 4^{+} \mathrm{T}$ cells defined by the expression of interferon- $\gamma$ and interleukin-17. $\mathbf{a}-\mathbf{b}$ Representative flow cytometry of Th1 and Th17 cells were shown. $\mathbf{c}-\mathbf{d}$ The proportions of subsets among $\mathrm{CD}^{+} \mathrm{T}$ cells in never-smokers and smokers with normal lung function, and patients with COPD. Data were presented as median (IQR). Horizontal lines indicate median values. A $p$ value $<0.05$ was considered statistically significant

Diego, CA, USA) according to the manufacturer's recommendations with the sensitivity of $2 \mathrm{pg} / \mathrm{ml}, 8.6 \mathrm{pg} / \mathrm{ml}$, and $0.5 \mathrm{pg} / \mathrm{ml}$, respectively.

\section{Statistical analysis}

Parametric data were depicted as a mean and SD or as median and IQR when appropriate. For data not distributed normally, across-group comparison of three groups was made using the nonparametric Kruskal-Wallis test. When the test detected statistical significance, post hoc analysis for comparison between two groups was performed by the Mann-Whitney test. Correlations were analyzed by Spearman's rank correlation coefficients.

\section{Results}

Demographic and clinical characteristics of the study population

The demographic and clinical characteristics of the patients with COPD, smokers and never-smokers with normal lung function were summarized in Table 1. There was no statistical difference in age and sex ratio among the groups. The lung function parameters were significantly different among the groups (all $p<0.001$ ). There was no difference in smoking history of smokers and COPD patients. There were 17 current smoker and 29 exsmoker COPD patients who were using ICS, including 20 GOLD I-II and 26 GOLD III-IV patients.

Frequencies of circulating subpopulations of total $\mathrm{CD} 4^{+} \mathrm{T}$ cells in patients with COPD, smokers and never-smokers We first investigated the cytokine profiles of IFN- $\gamma$ and IL-17 in CD4 + T cells in peripheral blood from the study participants using flow cytometry. Proportions of Th1 cells were significantly increased in patients with COPD (median 26.30\%) compared with never-smokers (median $19.75 \%, p<0.001$ ) and smokers (median $20.60 \%, p<0.01$ ), and there was a trend for increase in smokers compared with never-smokers (Fig. 1a, Fig. 2a and c). 
A

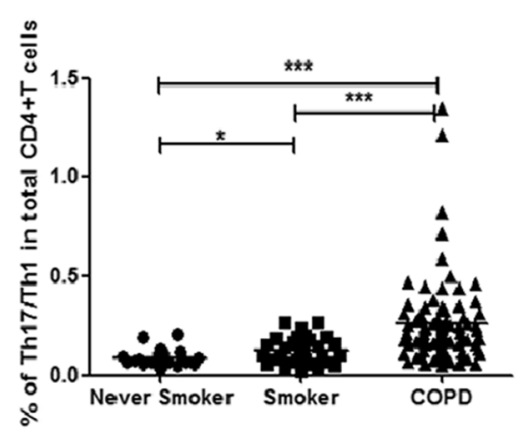

C

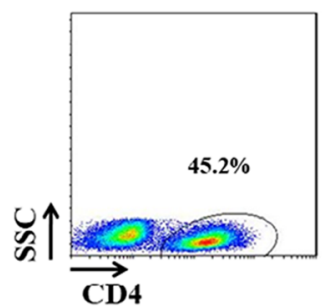

B

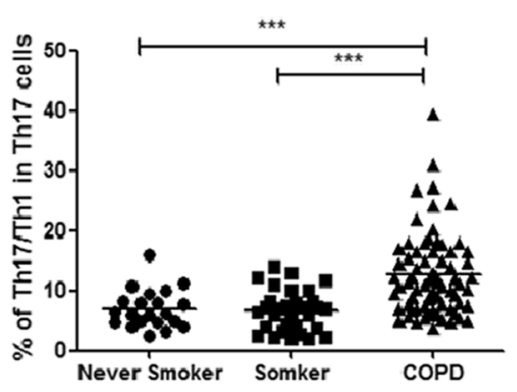

Fig. 3 Expression of dual-positive Th17/Th1cells in peripheral blood from never-smokers and smokers with normal lung function, and patients with COPD. The CD4 + T cell population was analyzed for production of interferon- $\gamma$ and interleukin-17. a-b Frequencies of Th17/Th1 cells among CD4 $^{+} T$ cells and Th17 cells in never-smokers, smokers and patients with COPD. c Representative flow cytometry of Th17/Th1 cells were shown. Data were presented a median (IQR). Horizontal lines indicate median values. A $p$ value $<0.05$ was considered statistically significant

Patients with COPD showed significantly increased frequencies of Th17 cells in total $\mathrm{CD}^{+} \mathrm{T}$ cells (median $1.90 \%$ ), in comparison to never-smokers (median 0.99\%, $p<0.05$ ) and smokers (median 1.46\%, $p<0.01$ ). And there was a higher percentage of Th17 cells in smokers than in never-smokers $(p<0.05)$ (Fig. 1b, Fig. 2b and d).

\section{Detection of dual-positive Th17/Th1 cells in peripheral blood from patients with COPD, smokers and never- smokers}

In patients with COPD, the proportions of Th17/Th1 cells, identified as $\mathrm{CD} 4^{+} \mathrm{IFN}-\gamma^{+} \mathrm{IL}-17^{+}$, among CD4 cells (median 0.203\%) in the peripheral blood were significantly higher compared with never-smokers (median $0.075 \%, p<0.001$ ) and smokers (median 0.107\%, $p<$ 0.001) (Fig. 1c and Fig. 3a). Furthermore, significantly higher frequencies of Th17/Th1 cells among Th17 cells were observed in COPD patients (median 11.01\%) compared with never-smokers (median 6.14\%, $p<0.001$ ) and smokers (median $7.15 \%, p<0.001$ ), suggesting increased differentiation of Th17 cells to Th17/Th1 cells in COPD (Fig. 3b). There also was a higher percentage of Th17/ Th1 cells in smokers than in never-smokers $(p<0.05)$ (Fig. 3a and b). Moreover, the frequencies of Th17/Th1 cells among total $\mathrm{CD}^{+} \mathrm{T}$ cells in COPD patients using
ICS (median $0.238 \%$ ) were significantly higher compared with COPD patients not using ICS (median $0.176 \%, p<$ 0.05; Fig. 1i).

\section{Correlations between frequencies of Th17/Th1 cells and} $\mathrm{FEV}_{1} \%$ in patients with COPD

To evaluate a possible correlation with disease severity, we analyzed the distribution of $\mathrm{CD}^{+} \mathrm{T}$ cell subsets within the COPD population with different $\mathrm{FEV}_{1} \%$ predicted values. There were no correlation observed between the percentages of Th1 cells and $\mathrm{FEV}_{1} \%$ predicted values $(r=-0.052, p=0.639$; Fig. $4 \mathrm{a})$. There was a negative correlation between the percentages of circulating Th17 cells and $\mathrm{FEV}_{1} \%$ predicted values $(r=-0.265$, $p<0.05$; Fig. 4b). Moreover, increased percentages of circulating Th17/Th1 cells in COPD patients were inversely correlated with $\mathrm{FEV}_{1} \%$ predicted values $(r=-$ 0.244, $p<0.05$; Fig. 4c). Patients in GOLD stage IV had higher proportions of Th17/Th1 cells when compared with stage I patients $(p<0.05$; Fig. $4 \mathrm{~d})$.

\section{Effects of smoking on frequencies of Th17/Th1 cells in patients with COPD}

To assess the potential impact of current smoking on Th17/Th1 cells, we examined the differences in Th17/Th1 

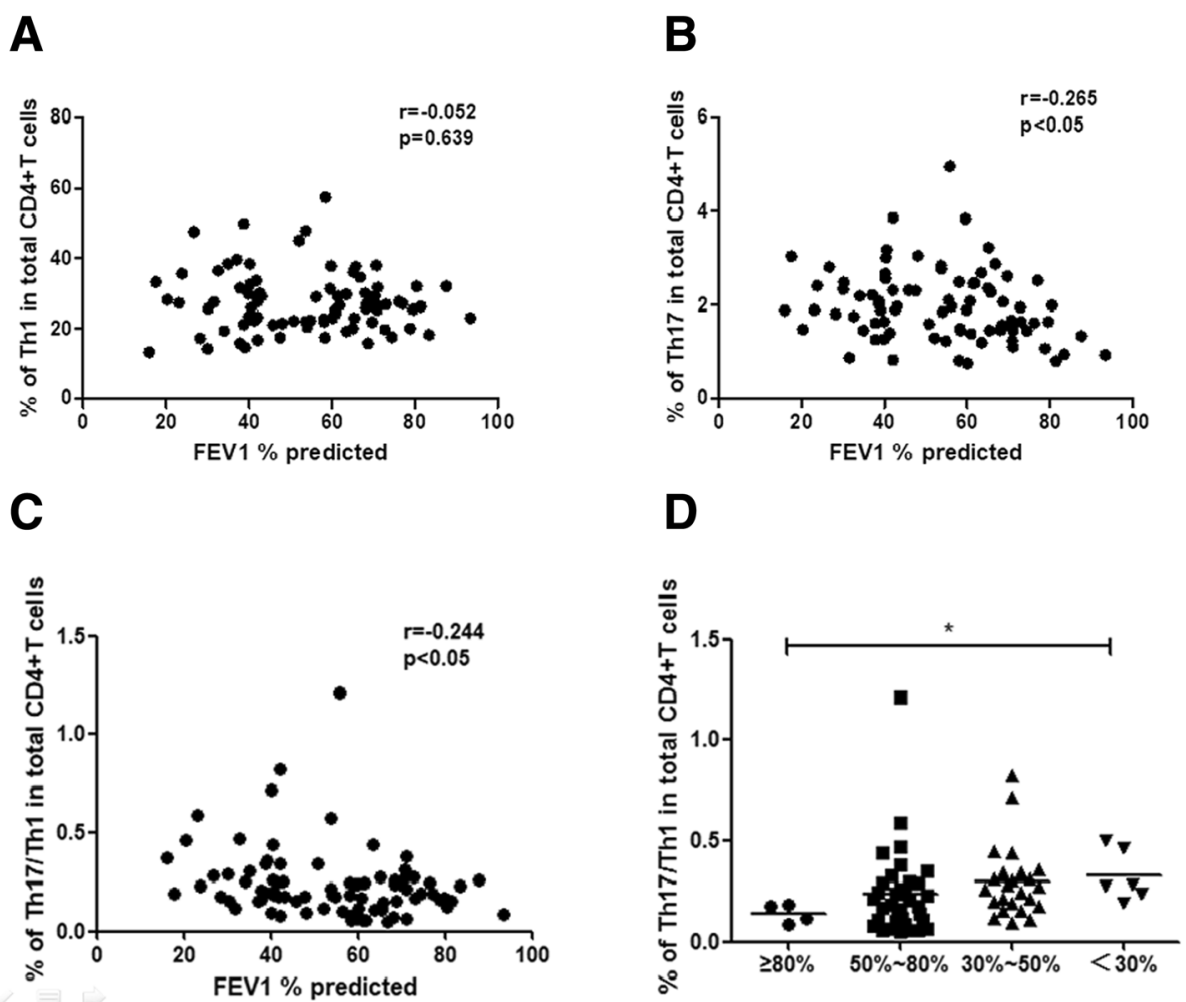

Fig. 4 Correlations between frequency of Th17/Th1 cells with lung function in patients with COPD. Correlations between frequency of (a) Th1 cells, b Th17 cells, $\mathbf{c}$ Th17/Th1 cells with forced expiratory volume in $1\left(\mathrm{FEV}_{1}\right) \%$ predicted value. $\mathbf{d}$ Proportion of Th17/Th1 cells in COPD patients with different Global Initiative for Chronic Obstructive Lung Disease (GOLD) stages. A p value $<0.05$ was considered statistically significant

cells between current and ex-smoker COPD populations. We found no differences in the percentages of Th17 cells between current and ex-smoker COPD patients $(p<0.05$; Fig. 5a). Interestingly, the frequencies of Th17/Th1 cells among total $\mathrm{CD}^{+} \mathrm{T}$ cells in current smoker COPD patients (median $0.261 \%$ ) were significantly higher compared with ex-smoker COPD patients (median $0.177 \%, p<0.05$; Fig. 5b). Furthermore, current smoker COPD patients had higher proportions of Th17/Th1 cells among Th17 cells (median 12.46\%) compared with ex-smoker COPD patients, suggesting a potential effect of cigarette smoke exposure on differentiation of Th17 cells to Th17/Th1 cells in COPD (median 10.09\%, $p<0.05$; Fig. 5c). In addition, there was a positive correlation between the percentages of circulating Th17/Th1 cells and pack-years of smoking $(r=0.352, p<0.01$; Fig. $5 \mathrm{~d})$.

\section{Plasma concentrations of IL-6, TGF- $\beta 1$ and IL-12 in} patients with COPD, smokers and never-smokers

We examined the concentrations of plasma cytokines believed to drive Th17 cell differentiation and further conversion to Th17/Th1 cells. In plasma from patients with COPD patients, the concentrations of IL-6, TGF- $\beta 1$ and IL12 were significantly higher compared with never-smokers $(p<0.001, p<0.001, p<0.01$, respectively) and smokers $(p<0.001, p<0.01, p<0.01$, respectively) (Fig. 6a-c).

\section{Discussions}

Th17 cells are a recently identified $\mathrm{CD}^{+} \mathrm{T}$ subset with pro-inflammatory actions, and are associated with human autoimmune diseases. IL-17A secretion is not sufficient to define the pathogenic activity of Th17 cells, and not all Th17 cells are pathogenic [12]. Function and phenotypic heterogeneity of human Th17 is a considerable barrier for understanding their contribution in diseases. Emerging data have identified IFN- $\gamma$ and IL-17 dual-positive Th17/Th1 cells as potentially pathogenic Th17 cells [12, 14, 16-22]. A study by Cosmi et al found that a shifting from Th17 cells to Th17/Th1 cells occurred in synovial fluid of juvenile idiopathic arthritis patients, and the frequencies of Th17/ Th1 cells were higher and positively correlated with parameters of inflammation [17]. Harbour et al showed that transition of Th17 cells to Th1-like cells was required for pathogenesis of colitis [18]. In lymphopenic mice, type 1 insulin-dependent diabetes was induced by Th17 cells only after their conversion into Th1 cells, and the onset of the disease was prevented by anti- IFN- $\gamma$, but not anti-IL-17 neutralizing antibody [19]. 

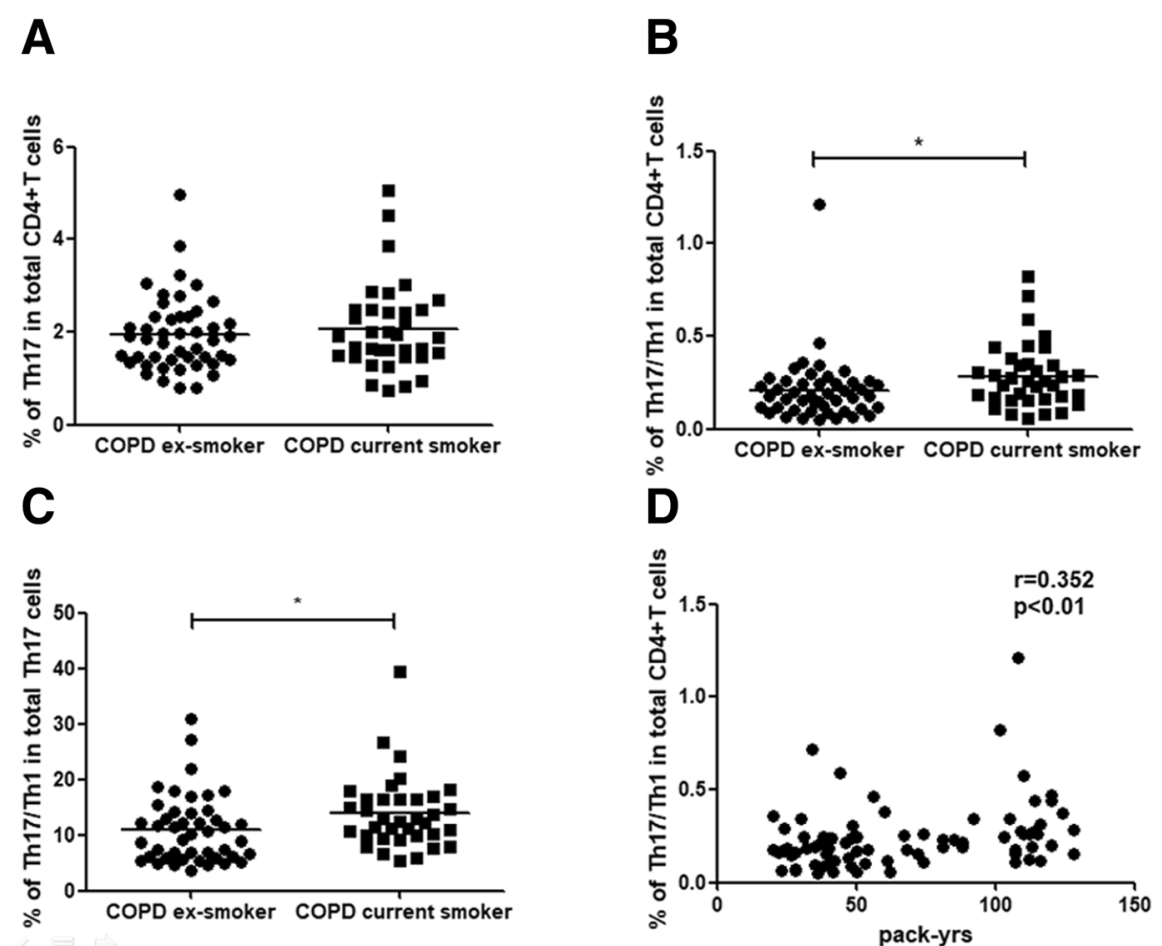

Fig. 5 Effect of current smoking status on proportions of Th17 and Th17/Th1 cells in patients with COPD. a-c Frequencies of Th17 cells and Th17/ Th1 cells in current smokers and ex-smoker COPD patients. $\mathbf{d}$ Correlations between frequency of Th17/Th1 cells with pack-years of smoking. Data were presented a median (IQR). Horizontal lines indicate median values. A $p$ value $<0.05$ was considered statistically significant

As COPD is a lung disease with significant systemic inflammation, we hypothesized that conversion of Th17 cells to Th17/Th1 cells may occur in the periphery and associate with disease manifestations. Here, we found, for the first time to our knowledge, that percentages of Th17/Th1 cells from COPD patients not only increased among CD4 cells, but also among Th17 cells, compared with smokers and never-smokers with normal lung function. These data suggest that the increased proportion of Th17/Th1 cells among $\mathrm{CD}^{+} \mathrm{T}$ cells was not only due to increased number of Th17 cells, but also due to increased late differentiation of Th17 cells to Th17/Th1 cells. More importantly, we revealed a negative correlation between the frequency of circulating Th17/Th1 cells and $\mathrm{FEV}_{1} \%$ predicted, suggesting a role of these cells in COPD pathogenesis.

Another interesting finding emerging from our study was the demonstration that the percentages of Th17/ Th1 cells among CD $4+\mathrm{T}$ cells, as well as among Th17 cells, were significantly higher in current smoker COPD patients than in ex-smoker COPD patients, and positively correlated with pack-years of smoking, although there was no difference in the percentages of Th17 cells among COPD smokers and ex-smokers. A study by Ammitzbøll et al found that GPR15 + T cells were associated with a Th17/Th1 phenotype and correlated with disease activity in multiple sclerosis smokers [23]. Smoking was shown to induce the expression and methylation of GPR15, and methylation of GPR15 was linked to the cumulative exposure to smoking and could be reversed by smoking cessation [24, 25]. Recently, Bauer et al found that tobacco smoking induced an excess in the GPR15-expressing T cells subsets [26]. It is conceivable that conversion of Th17 cells to Th17/Th1 cells in COPD may be driven by smoking exposure via induction of GPR15, which warrants further investigation.

Since Th17 plasticity is driven by inflammatory conditions [14], we supposed that the increased Th17 plasticity was related to the systemic inflammation of COPD. We found significantly higher levels of IL-12 in the plasma from COPD patients compared with smokers and healthy controls, suggesting that the circulating microenvironment in COPD may also contribute to the late plasticity of Th17 cells to Th17/Th1 cells.

Our study had several limitations. We investigated only peripheral blood, not bronchoalveolar lavage or lung tissue specimens, which may be more relevant to the pathogenesis of COPD. In addition, some of the COPD patients had used ICS, and therefore the possibility of an effect of ICS on the results cannot be excluded, although studies found no correlations between ICS and T cells in COPD, except for $\mathrm{IL}-17 \mathrm{~F}^{+} \mathrm{CD} 4^{+} \mathrm{T}$ cells [4]. In our study COPD 

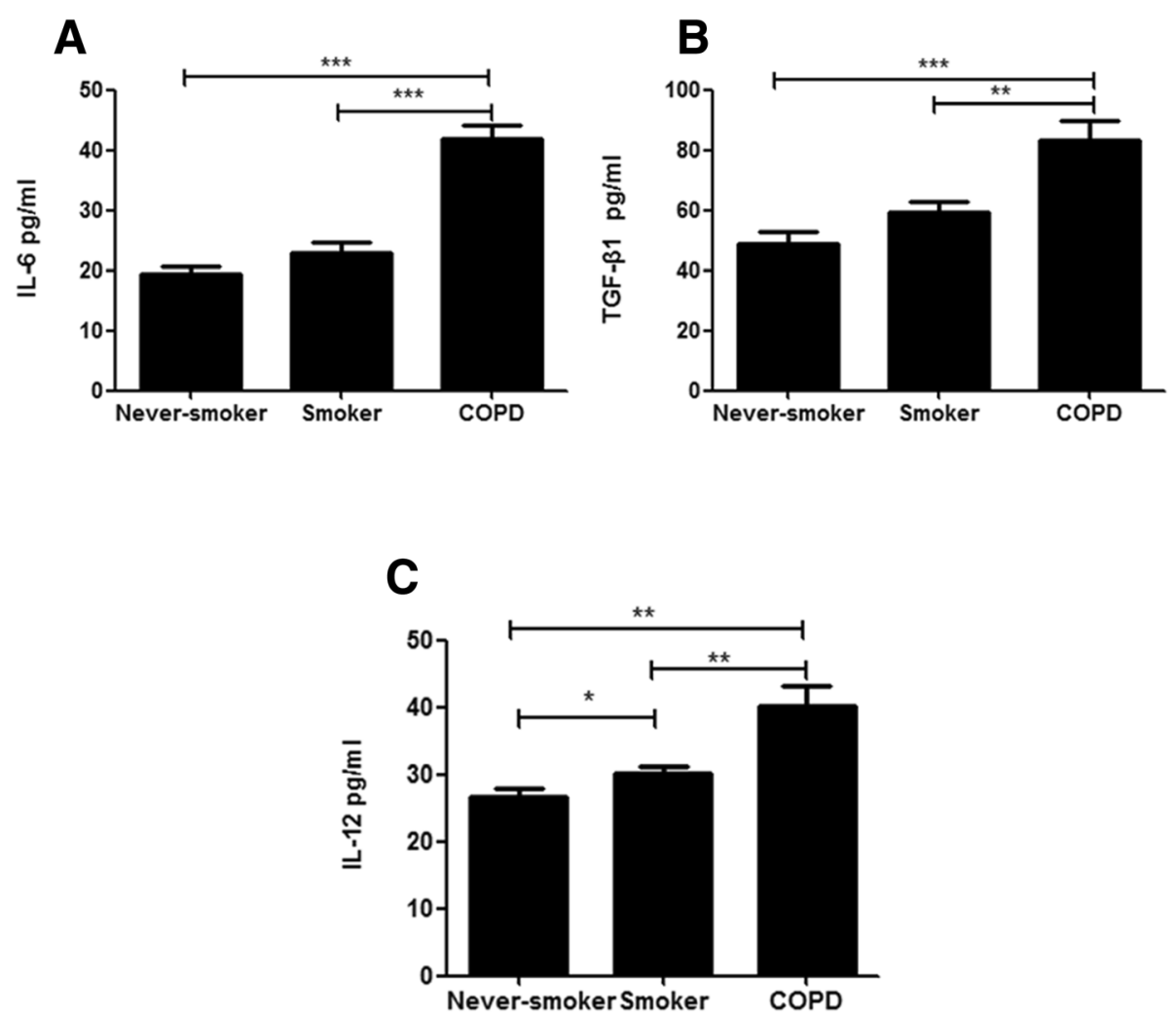

Fig. 6 The concentrations of plasma cytokines. a Interleukin-6, b transforming growth factor- $\beta 1$, and (c) Interleukin- 12 from never-smokers and smokers with normal lung function, and patients with COPD. A $p$ value $<0.05$ was considered statistically significant

patients using ICS had a higher frequency of Th17/Th1 cells, this maybe due to the higher proportion of GOLD III and IV patients who were taking this medicine, considering the negative correlation between the frequency of Th17/Th1 cells and $\mathrm{FEV}_{1} \%$ predicted.

\section{Conclusions}

In summary, our study provided new data for understanding the potential role of a new subset of Th17/Th1 cells in COPD. These findings may facilitate our understanding of the underlying mechanisms for systemic inflammation and disease progression in COPD.

\section{Abbreviations}

COPD: Chronic obstructive pulmonary disease; ELISA: Enzyme-linked immunosorbent assay; $F_{E V}$ : Forced expiratory volume in $1 \mathrm{~s}$; FVC: Forced vital capacity; GOLD: Global Initiative for Chronic Obstructive Lung Disease; ICS: Inhaled corticosteroid; IFN- - : Interferon- $\gamma$; IL-17: Interleukin-17; PBMC: Peripheral blood mononuclear cells; Th1: T helper 1; TNF$\beta 1$ : Transforming growth factor- $\beta 1$

\section{Acknowledgments}

We thank Xichun Zhang for help with the pulmonary function tests. We thank Dr. Peng Bai and Dr.Xiaofang Liu of Department of Respiratory Medicine, Beijing Tongren Hospital, Capital Medical University, Beijing, China, for their assistance in this study.
Authors' contributions

WHX, RML and YCS contribute to the study conception and design, data acquisition, data analysis and interpretation. WHX wrote the first draft of manuscript. YCS contributed to critical revision of the manuscript for important intellectual content. All authors read and approved the final manuscript.

\section{Funding}

The study was supported by the National Natural Science Foundation of China (NSFC) (No.81470239, No. 81770040).

Availability of data and materials

The datasets used and/or analyzed during the current study available from the corresponding author on reasonable requests.

Ethics approval and consent to participate

The protocol was approved by the research ethical committee of Beijing Tongren Hospital, under the following reference number: (TRECKT 2008-14). All subjects provided written informed consent.

\section{Consent for publication}

Not applicable.

\section{Competing interests}

The authors declare that they have no competing interests.

\section{Author details}

'Department 2 of Respiratory Medicine, Beijing Children's Hospital, Capital Medical University, National Center for Children's Health, Beijing, China. ${ }^{2}$ Department of Respiratory Medicine, Beijing Tongren Hospital, Capital Medical University, Beijing, China. ${ }^{3}$ Department of Respiratory Medicine, Beijing Daxing Teaching Hospital, Capital Medical University, Beijing, China. 
${ }^{4}$ Department of Respiratory and Critical Care Medicine, Peking University Third Hospital, Beijing, China.

Received: 17 November 2018 Accepted: 18 July 2019

Published online: 26 July 2019

\section{References}

1. Hogg JC, Chu F, Utokaparch S, et al. The nature of small-airway obstruction in chronic obstructive pulmonary disease. N Engl J Med. 2004;350:2645-53.

2. Global initiative for chronic obstructive lung disease (GOLD). Global strategy for diagnosis, management and prevention of COPD. 2015

3. Gan WQ, Man SP, Senthilselvan A, et al. Association between chronic obstructive pulmonary disease and systemic inflammation: a systematic review and a meta-analysis. Thorax. 2004;59(7):574-80.

4. Paats MS, Bergen IM, Hoogsteden HC, et al. Systemic CD4+ and CD8+ T-cell cytokine profiles correlate with GOLD stage in stable COPD. Eur Respir J. 2012:40(2):330-7.

5. Hou J, Sun Y, Hao Y, et al. Imbalance between subpopulations of regulatory T cells in COPD. Thorax. 2013;68(12):1131-9.

6. Stefano AD, Caramori G, Gnemmi I, et al. T helper type 17-related cytokine expression is increased in the bronchial mucosa of stable chronic obstructive pulmonary disease patients. Clin Exp Immunol. 2009;157(2):316-24.

7. Eustace $A$, Smyth $L$, Mitchell $L$, et al. Identification of cells expressing IL-17A and IL-17F in the lungs of patients with COPD. Chest. 2011;139(5):1089-100.

8. Vargasrojas Ml, Ramirezvenegas A, Limoncamacho L, et al. Increase of Th17 cells in peripheral blood of patients with chronic obstructive pulmonary disease. Respir Med. 2011;105(11):1648-54.

9. Park $\mathrm{H}, \mathrm{Li} Z$, Yang $\mathrm{XO}$, et al. A distinct lineage of CD4 T cells regulates tissue inflammation by producing interleukin 17. Nat Immunol. 2005;6(11):1133-41.

10. Korn T, Bettelli E, Oukka M, et al. IL-17 and Th17 cells. Annu Rev Immunol. 2009;27(1):485-517.

11. Roos AB, Sanden C, Mori M, et al. IL-17A is elevated in end-stage chronic obstructive pulmonary disease and contributes to cigarette smoke-induced lymphoid Neogenesis. Am J Respir Crit Care Med. 2015;191(11):1232-41.

12. Lee $\mathrm{Y}$, Awasthi $\mathrm{A}$, Yosef $\mathrm{N}$, et al. Induction and molecular signature of pathogenic TH17 cells. Nat Immunol. 2012;13(10):991-9.

13. Lee $\mathrm{YK}$, Turner $\mathrm{H}$, Maynard $\mathrm{CL}$, et al. Late developmental plasticity in the $\mathrm{T}$ helper 17 lineage. Immunity. 2009;30(1):92-107.

14. Nistala K, Adams S, Cambrook H, et al. Th17 plasticity in human autoimmune arthritis is driven by the inflammatory environment. Proc Natl Acad Sci U S A. 2010;107(33):14751-6.

15. Boniface K, Blumenschein WM, Brovontporth K, et al. Human Th17 cells comprise heterogeneous subsets including IFN- $\gamma$-producing cells with distinct properties from the Th1 lineage. J Immunol. 2010;185(1):679-87.

16. Ramesh R, Kozhaya L, Mckevitt K, et al. Pro-inflammatory human Th17 cells selectively express P-glycoprotein and are refractory to glucocorticoids. J Exp Med. 2014;211(1):89-104.

17. Cosmi L, Cimaz R, Maggi L, et al. Evidence of the transient nature of the Th17 phenotype of CD4+CD161+ T cells in the synovial fluid of patients with juvenile idiopathic arthritis. Arthritis Rheum. 2014, 63(8):2504-15.

18. Harbour SN, Maynard CL, Zindl CL, et al. Th17 cells give rise to Th1 cells that are required for the pathogenesis of colitis. Proc Natl Acad Sci U S A. 2015; 112(22):7061-6.

19. Martinorozco N, Chung Y, Chang SH, et al. Th17 cells promote pancreatic inflammation but only induce diabetes efficiently in lymphopenic hosts after conversion into Th1 cells. Eur J Immunol. 2010, 39(1):216-24.

20. Ramstein J, Broos CE, Simpson LJ, et al. IFN- $\gamma$-producing T-helper 17.1 cells are increased in sarcoidosis and are more prevalent than T-helper type 1 cells. Am J Respir Crit Care Med. 2016;193(11):1281-91.

21. Leonardi $C L$, Kimball AB, Papp KA, et al. Efficacy and safety of ustekinumab, a human interleukin-12/23 monoclonal antibody, in patients with psoriasis: 52-week results from a randomised, double-blind, placebo-controlled trial (PHOENIX 2). Lancet. 2008;371(9625):1675-84.

22. Hueber W, Sands BE, Lewitzky S, et al. Secukinumab, a human anti-IL-17A monoclonal antibody, for moderate to severe Crohn's disease: unexpected results of a randomised, double-blind placebo-controlled trial. Gut. 2012; 61(12):1693-700

23. Ammitzboll C, Von Essen MR, Bornsen L, et al. GPR15+ T cells are Th17 like, increased in smokers and associated with multiple sclerosis. J Autoimmun. 2019;97:114-21.
24. Koks S, Koks G. Activation of GPR15 and its involvement in the biological effects of smoking. Exp Biol Med. 2017;242(11):1207-12

25. Koks G, Uudelepp M, Limbach M, et al. Smoking-induced expression of the GPR15 gene indicates its potential role in chronic inflammatory pathologies. Am J Pathol. 2015;185(11):2898-906.

26. Bauer M, Hackermuller J, Schor J, et al. Specific induction of the unique GPR15 expression in heterogeneous blood lymphocytes by tobacco smoking. Biomarkers. 2018;2:1-8.

\section{Publisher's Note}

Springer Nature remains neutral with regard to jurisdictional claims in published maps and institutional affiliations.
Ready to submit your research? Choose BMC and benefit from:

- fast, convenient online submission

- thorough peer review by experienced researchers in your field

- rapid publication on acceptance

- support for research data, including large and complex data types

- gold Open Access which fosters wider collaboration and increased citations

- maximum visibility for your research: over $100 \mathrm{M}$ website views per year

At $\mathrm{BMC}$, research is always in progress.

Learn more biomedcentral.com/submissions 